\title{
WISATA KULINER DI PANTAI INDAH KAPUK
}

\author{
Vina Angelina ${ }^{1)}$, Mieke Choandi $^{2)}$ \\ 1)Program Studi S1 Arsitektur, Fakultas Teknik, Universitas Tarumanagara, vina.angelina 59@gmail.com \\ 2) Program Studi S1 Arsitektur, Fakultas Teknik, Universitas Tarumanagara, mieke@stu.untar.ac.id
}

\begin{abstract}
Abstrak
Pada jaman milenial, tren sangatlah mudah tersebar karena kehadiran sosial media. Kaum Milenial dengan rasa ingin tahu yang tinggi, sebagai "digital native", dapat dengan mudah mencari tahu tren apa yang sedang terjadi saat itu. Dan biasanya akan berusaha untukmelakukan tren tersebut. Hal itu dikarenakan kaum milenial gemar untuk mencoba sesuatuyang baru. Selain itu, pengalaman yang didapatkan akan selalu diabadikan melalui foto yang kemudian akan dipamerkan di sosial media. Salah satu tren yang paling 'hits' di jaman ini adalah kuliner. Ketika kuliner digabungkan dengan sosial media yang semarak di kalangan milenial, akan ada aktivitas menyebarkan konten berupa kuliner pada sosial media. Karena dampak yang cukup besar dari aktivitas itu, kini restoran berbondong-bondong menyajikan konsep tempat makan unik dengan penampilan makanan yang menarik dan desain tempat makan yang berbeda. Kaum millennial juga memburu jenis tempat makan seperti itu agar dapat dipamerkan di media sosial. Dengan menghadirkan sebuah arsitektur yang merupakan wisata kuliner diharapkan dapat menjadi wadah kaum milenial untuk menyalurkan hobi akan kuliner sambil belajar untuk melestarikan lingkungan.
\end{abstract}

Kata kunci: Kuliner; Milenial; Tren; Wisata

\begin{abstract}
At millennial era, trends are very easily spread due to the presence of social media. Millennials with high curiosity, as "digital native" can easily find out what trends are happening at that time. And usually will try to do that trend. That is because millennials like to try something new, besides, the experience gained will always be perpetuated through photos which will then be exhibited on social media. One of the trends of the most 'hits' in this era is culinary. When culinary is combined with vibrant social media in millennials, there will be activities to spread culinary content on social media. Because of the considerable impact of the activity, now restaurants are flocking to present the concept of a unique dining place with attractive food performances and different dining places. Millennials also hunt for such types of places to be exhibited on social media. By presenting an architecture which is an culinary tour, it is hoped that it can become a forum for millennials to channel culinary hobbies while learning to preserve the environment.
\end{abstract}

Keywords: Culinaru; Millenial; Tourism; Trend

\section{PENDAHULUAN}

Pada masa kini, tren sangatlah mudah tersebar karena kehadiran sosial media. Kaum Millennial dengan rasa ingin tahu yang tinggi, sebagai "digital native" dapat dengan mudah mencari tau tren apa yang sedang terjadi saat itu. Dan biasanya akan berusaha untuk melakukan tren tersebut. Hal itu dikarenakan kaum millennial gemar untuk mencoba sesuatu yang baru, selain itu, pengalaman yang didapatkan akan selalu diabadikan melalui foto yang kemudian akan dipamerkan di sosial media. Salah satu tren yang paling 'hits' di jaman ini adalah kuliner. Ketika kuliner digabungkan dengan sosial media yang semarak di kalangan millennials, akan ada aktivitas menyebarkan konten berupa kuliner pada sosial media. Karena aktivitas tersebut pula, muncullah yang namanya food-blogger. Food-blogger adalah penulis blog yang berisikan ulasan mengenai restoran atau makanan yang ia coba. Dan $95 \%$ foodblogger memiliki media sosial, guna menyebarluaskan postingan blog nya. Food-blogger memiliki dampak yang sangat besar terutama di kehidupan millennial di Indonesia. Tren 'Zero 
Waste' juga sedang semarak sejak tahun 2018. Semarak nya tren 'zero waste' ini juga disebarluaskan oleh influencer di media sosial dan memberi pengaruh kepada banyak orang terutama pengguna media sosial.

\section{KAJIAN LITERATUR}

\section{Tipe - Perilaku}

Manusia sebagai makhluk sosial tidak pernah lepas dari lingkungan yang membentuk diri mereka. Diantara sosial dan arsitektur dimana bangunan yang didesain manusia, secara sadar atau tidak sadar, mempengaruhi pola perilaku manusia yang hidup didalam arsitektur dan lingkungannya tersebut. Sebuah arsitektur dibangun untuk memenuhi kebutuhan manusia. Dan sebaliknya, dari arsitektur itulah muncul kebutuhan manusia yang baru kembali (Tandal dan Egam, 2011)

Menurut Donna P. Duerk, dalam bukunya yang berjudul Architectural Programming (1993) dijelaskan bahwa : manusia dan perilakunya adalah bagian dari system yang menempati tempat dan lingkungan tidak dapat dipisahkan secara empiris. Karena itu perilaku manusia selalu terjadi pada suatu tempat dan dapat dievaluasi secara keseluruhan tanpa pertimbangan factor-faktor lingkungan.

a. Lingkungan yang mempengaruhi perilaku manusia.

Orang cenderung menduduki suatu tempat yang biasanya diduduki meskipun tempat tersebut bukan tempat duduk. Misalnya: susunan anak tangga didepan rumah, bagasi mobil yang besar, pagar yang rendah dan sebagainya.

b. Perilaku manusia yang mempengaruhi lingkungan

Pada saat orang cenderung memilih jalan pintas yang dianggapnya terdekat dari pada melewati pedestrian yang memutar. Sehinga orang tersebut tanpa sadar telah membuat jalur sendiri meski telah disediakan pedestrian.

Menurut Y.B Mangun Wijaya dalam buku Wastu Citra (1992). Arsitektur berwawasan perilaku adalah Arsitektur yang manusiawi, yang mampu memahami dan mewadahi perilakuperilaku manusia yang ditangkap dari berbagai macam perilaku, baik itu perilaku pencipta, pemakai, pengamat juga perilaku alam sekitarnya. Disebutkan pula bahwa Arsitektur adalah penciptaan suasana, perkawinan guna dan citra. Guna merujuk pada manfaat yang ditimbulkan dari hasil rancangan. Citra merujuk pada image yang ditampilkan oleh suatu karya Arsitektur. Citra lebih berkesan spiritual karena hanya dapat dirasakan oleh jiwa kita. Dari pernyataan di atas dapat dikatakan bahwa mengapa guna dan citra yang sesuai tidak lepas dari berbagai perilaku yang berpengaruh dalam sebuah karya, baik itu perilaku pencipta, perilaku pemakai, perilaku pengamat juga menyangkut perilaku alam dan sekitarnya. Pembahasan perilaku dalam buku wastu citra dilakukan satu persatu menurut beragamnya pengertian Arsitektur, sebagai berikut: 1) Perilaku manusia didasari oleh pengaruh sosial budaya yang juga mempengaruhi terjadinya proses Arsitektur; 2) Perilaku manusia yang dipengaruhi oleh kekuatan religi dari pengaruh nilai-nilai kosmologi; 3) Perilaku alam dan lingkungan mendasari perilaku manusia dalam berArsitektur; 4) Dalam berarsitektur terdapat keinginan untuk menciptakan perilaku yang lebih baik.

\section{Arsitektur Membentuk Perilaku Manusia}

Manusia membangun bangunan demi pemenuhan kebutuhan pengguna, yang kemudian bangunan itu membentuk perilaku pengguna yang hidup dalam bangunan tersebut dan mulai membatasi manusia untuk bergerak, berperilaku, dan cara manusia dalam menjalani kehidupan sosialnya. Hal ini menyangkut kestabilan antara arsitektur dan sosial dimana keduanya hidup berdampingan dalam keselarasan lingkungan. "Arsitektur membentuk Perilaku Manusia", dimana terjadi hubungan satu arah yaitu desain arsitektur yang dibangun mempengaruhi perilaku manusia sehingga membentuk perilaku manusia dari desain arsitektur tersebut. Perilaku Manusia membentuk Arsitektur 
Setelah perilaku manusia terbentuk akibat arsitektur yang telah dibuat, manusia kembali membentuk arsitektur yang telah dibangun atas dasar perilaku yang telah terbentuk, dan seterusnya. "Perilaku Manusia membentuk Arsitektur" dimana desain arsitektur yang telah terbentuk mempengaruhi perilaku manusia sebagai pengguna yang kemudian manusia mengkaji kembali desain arsitektur tersebut sehingga perilaku manusia membentuk kembali desain arsitektur yang baru

\section{Generasi Millennial}

Generasi millennial merupakan umat manusia yang lahir pada rentang tahun $1980-2000$. Generasi ini dikenal sebagai generasi yang penuh ide visioner, inofatif, memanfaatkan teknologi dan mementingkan prestasi kerja. Merupakan generasi dengan populasi terbanyak pada saat ini.

Menurut buku "Millennials" karya MIX MarComm, Generasi Millennials (2018) memiliki 10 karakter yaitu:
a. Melek digital
b. Konsumtif
c. Saving untuk sesuatu yang diinginkan
d. Knowledgeable
e. Digital sebagai media komunikasi
f. Menjadi entrepreneur tanpa persiapan
g. Mengutamakan fasilitas dan apresiasi di dunia kerja
h. Rise of the experiential
i. Radical Transparency
j. Fear of missing out (FOMO)

Tren-tren yang bermuncullan di kalangan generasi millennial dan dampaknya

Adapun kajian yang dilakukan disesuaikan dengan latar belakang dan kultur negara Indonesia. Hasilnya didapatkan 13 tren nilai dan habit generasi millennials yang berikut ini:

- Millenials Wannabe

- Sharing is cool

- 'How we consume'

- Digital entrepreneur

- Holiday experiencer
- Multi-tribes netizen

- Brand story matters

- Personal branding

- Attention seeker

- Click Activist.

\section{Kuliner}

Generasi milenial berperan dalam membentuk tren kuliner. Kebiasaan mereka bisa mengubah pola pikir masyarakat secara umum tentang kuliner.

Kemunculan tiap generasi mempengaruhi masyarakat secara keseluruhan. Tahun ini, giliran generasi milenial yang banyak berperan. Mereka yang ada di usia 19-35 tahun ini mengisi sebagian besar kelompok tenaga kerja produktif. Maka, tak heran para pelaku bisnis berlombalomba menarik perhatian mereka. Menciptakan berbagai produk yang mampu memenuhi kebutuhan para generasi milenial. Beberapa produk yang kiranya dipengaruhi kemunculan generasi milenial adalah produk makanan sehat ramah lingkungan dan paket online delivery bahan makanan siap masak. Nilai lebih berupa aspek sehat dan praktis dari kedua produk nampaknya jadi hal yang dicari generasi milenial.

Eve Turow, penulis buku A Taste of Generation Yum: How the Millennial Generation's Love for Organic Fare, Celebrity Chefs, and Microbrews Will Make or Break the Future of Food with The Atlantic mengatakan, "Kita telah dibentuk menjadi sebuah masyarakat yang terbiasa duduk di depan layar dan mengetik. Dan faktanya, hal ini tidak memuaskan semua panca indera kita." Turow menambahkan, "Lewat wawancara yang banyak saya lakukan, saya 
mendengar banyak orang (generasi milenial) menginginkan sesuatu yang nyata. Dapat mereka lihat, rasakan, cium, dan rasakan."

Di tahun 2017, para ahli menyoroti bagaimana generasi milennial akan membentuk pola konsumsi dan pikiran masyarakat secara keseluruhan tentang makanan. Dikutip dari Forbes (31/12), inilah beberapa prediksinya:

a. Makanan adalah perluasan kepribadian

b. Fotografi makanan makin penting untuk bisnis.

c. Lebih banyak masak.

\section{Carbon Footprint}

Carbon Footprint adalah jumlah total gas rumah kaca yang dihasilkan untuk mendukung aktivitas manusia secara langsung dan tidak langsung, biasanya dinyatakan dalam ton setara karbon dioksida (CO2). Gas rumah kaca, termasuk karbon dioksida, dapat dipancarkan melalui pembukaan lahan, produksi dan konsumsi makanan, bahan bakar, barang-barang manufaktur, bahan, kayu, jalan, bangunan, transportasi dan layanan lainnya. Dalam kebanyakan kasus, carbon footprint total tidak dapat dihitung secara tepat karena pengetahuan dan data yang tidak memadai tentang interaksi kompleks antara proses yang berkontribusi, termasuk pengaruh proses alami yang menyimpan atau melepaskan karbon dioksida. Ketika mengendarai mobil, mesin membakar bahan bakar yang menghasilkan $\mathrm{CO} 2$ dalam jumlah tertentu, tergantung pada konsumsi bahan bakarnya dan jarak mengemudi. (CO2 adalah simbol kimia untuk karbon dioksida). Ketika membeli makanan dan barang, produksi makanan dan barang juga mengeluarkan sejumlah $\mathrm{CO}$.

Indonesia adalah penghasil emisi gas rumah kaca terbesar kelima di dunia, terutama karena konversi hutannya dan lahan gambut yang kaya karbon. Pergeseran dalam penggunaan lahan ini memiliki konsekuensi ekologis dan sosial, karena hutan Indonesia adalah rumah bagi ribuan spesies tanaman dan hewan, dan 50-60 juta orang Indonesia bergantung langsung pada hutan untuk mata pencaharian mereka.

Laporan 'Dewan Nasional Perubahan Iklim' mengungkapkan bahwa degradasi dan perusakan lahan gambut ( 45 persen) dan hutan ( 35 persen) merupakan 80 persen dari emisi CO2 Indonesia 2,3 miliar ton per tahun. Proyek ini memproyeksikan emisi Indonesia akan naik 57 persen menjadi 3,6 miliar ton pada tahun 2030, sebagian besar disebabkan oleh penebangan yang berkelanjutan dan konversi ekosistem alami untuk pertanian dan perkebunan industri.

\section{METODE}

\section{Survey Lapangan}

Tapak berupa tanah kosong yang dipenuhi rumput dengan batas fisik yang berbeda-beda. sisi yang berhadapan dengan Yayasan Budha Tzu Chi Indonesia diberi batas fisik berupa pagar yang terbuat dari lempengan seng kemudian ada saluran air (got) yang mengalir, penghijauan dan jalur kendaraan. 

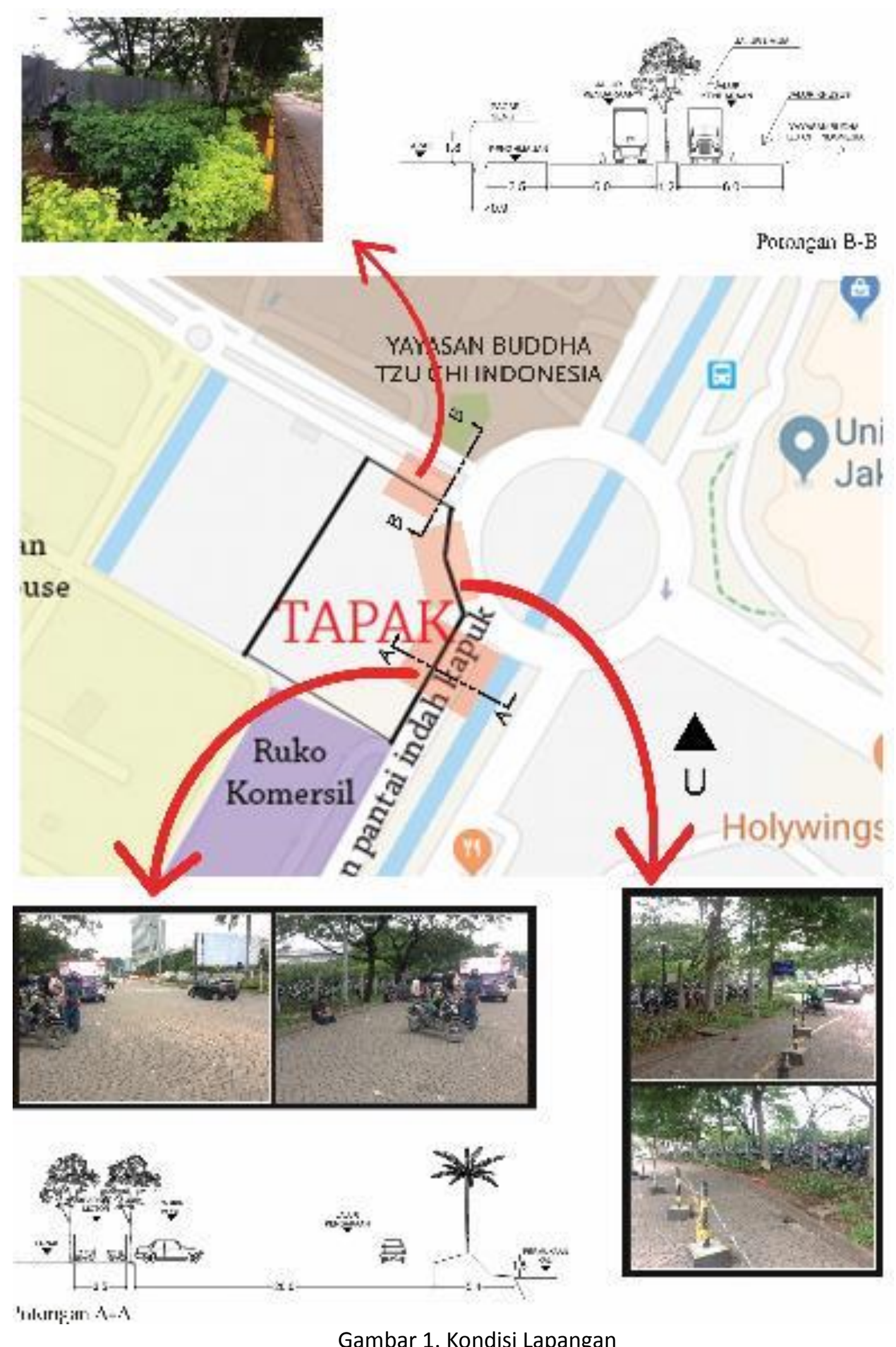

Gambar 1. Kondisi Lapangan

Sumber: Penulis, 2019

Sisi yang menghadap boulevard dan jalan Pantai Indah Kapuk memiliki batasan fisik berupa tiang seng dan penghijauan di depan sisi ini dialihfungsikan sebagai tempat parkir kendaraan (motor) pegawai ruko. 


\section{Metode Konvensional}

Survei

Sebelum memulai proses merancang, dilakukan survei untuk mengenal suatu kawasan terlebih dahulu. Dari survei kemudian didapatkan kondisi perilaku masyarakat sekitar dan kebiasaan yang menjadi budaya sekitar. Dari survei perilaku tersebut ditemukan 3 alternatif lahan yang berpotensi untuk dijadikan tapak perancangan.

\section{Analisa}

Kemudian hasil survei dan alternatif tapak dianalisa dengan table skor untuk mencari satu tapak yang paling berpotensi Setelah dianalisa, didapatkan satu tapak terpilih untuk dijadikan tapak perancangan.

Sintesa

Dari hasil Analisa dan survei, didapatkan hasil berupa fungsi yang dapat menjawab permasalahan dari jaman milenial dan kondisi tapak yang diambil.

\section{Referensi}

Mempelajari studi kasus dengan program yang sejenis.

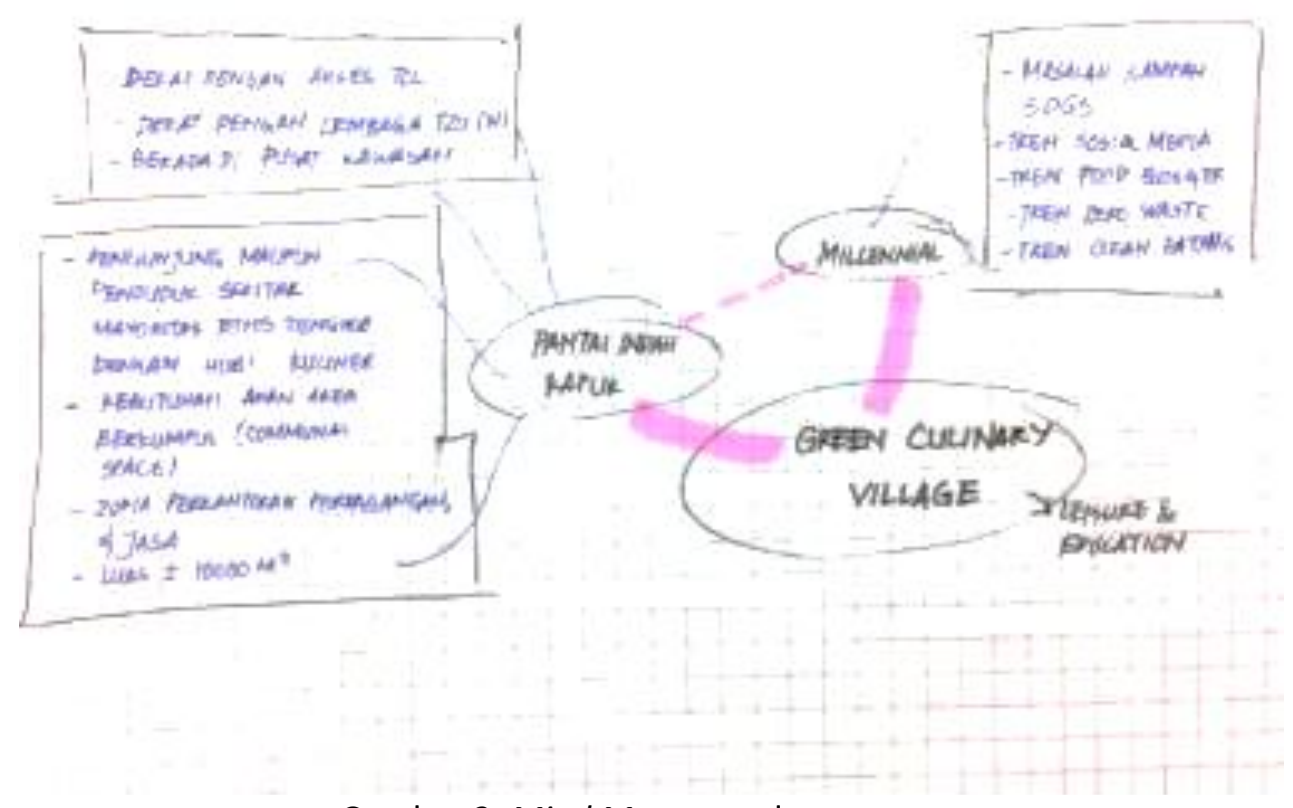

Gambar 2. Mind Map metode perancangan

Sumber: Penulis, 2019

\section{DISKUSI DAN HASIL}

Dari survey lapangan data-data diolah dikelompokan berdasarkan dengan subjek yang berkaitan. Data-data kemudian dianalisa dan digunakan untuk menjadi acuan awal mendesign.

Setelah melalui proses gubahan massa, pengaturan ruang dilakukan berdasarkan zonasi publik- privat dan hubungan antar program utama yang kemudian direalisasikan sebagai berikut: 


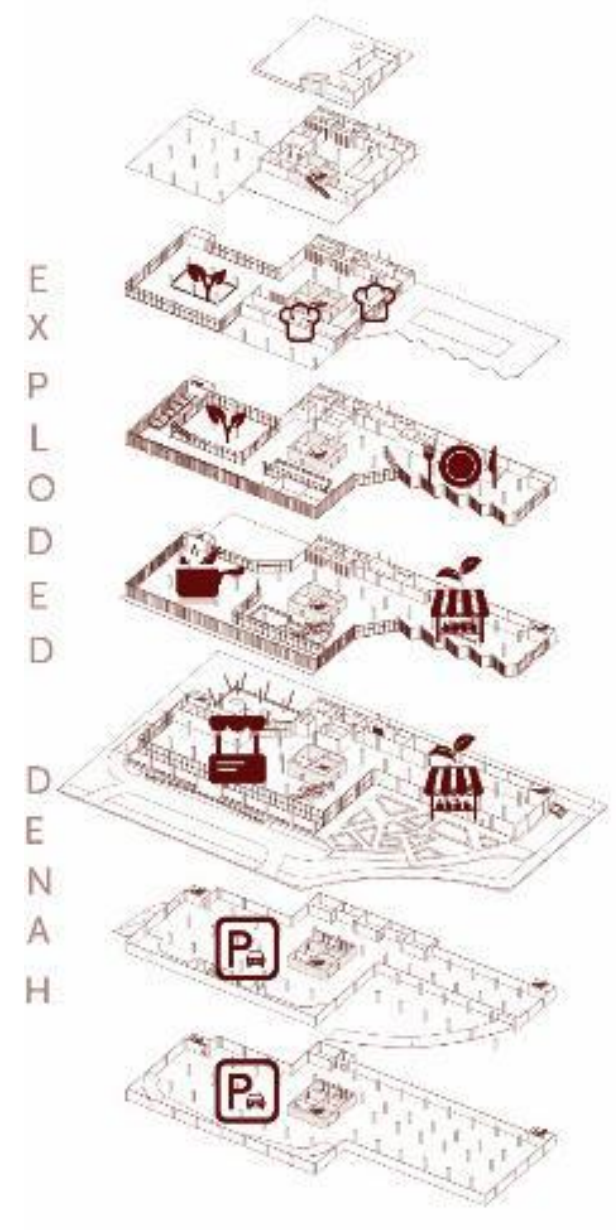

Rooftop: utilitas bangunan

Lantai 5: kantor pengelola dan ruang seminar

Lantai 4: area berkebun dan kelas memasak

Lantai 3: restoran dan area Berkebun

Lantai 2: area memasak umum dan organic market

Lantai 1: area bazaar, organic market dan taman terbuka untuk publik

Basement 1: parkir mobil \& motor dan utilitas bangunan

Basement 2: parkir mobil dan utilitas bangunan

\section{Gambar 3. Denah Exploded \\ Sumber: Penulis, 2019}

\section{KESIMPULAN DAN SARAN}

\section{Kesimpulan}

Milenial dengan rasa ingin tahu nya yang tinggi, selalu tertarik dengan hal-hal baru dan rela untuk mengeluarkan uang untuk pengalaman baru tersebut terutama dalam hal kuliner. Tujuan nya untuk disebarkan di media sosial atau memang hanya ingin merasakan sesuatu yang baru. Dengan tersebarnya di sosial media, pengalaman tersebut dapat menarik pengguna sosial media lainnya. Melalui fenomena tersebut, alangkah baik nya pengalaman tersebut memiliki sifat yang mendidik.

Sehubungan dengan masalah global yang banyak terjadi, salah satunya, carbon footprint. Milenial diajak untuk merasakan wisata kuliner yang menyenangkan sambil belajar untuk mengurangi penggunaan pestisida dan transportasi. Sifat milenial yang gemar untuk menyebarluaskan pengalamannya di media sosial terutama yang berperan besar yakni, food blogger, akan memberikan ketertarikan kepada pengguna media sosial lainnya untuk merasakan wisata kuliner yang menyenangkan namun mendidik.

Wisata Kuliner di Pantai Indah Kapuk didesain untuk publik dengan tujuan agar pengunjung dapat menikmati dan menyalurkan hobi akan kuliner sambil belajar untuk melestarikan lingkungan.

Saran

Adanya implementasi yang lebih baik dari organisasi ruang ke denah, agar tebrentuk sirkulasi yang lebih efisien. Mengeksplorasi lebih dalam lagi agar terbentuk pengalaman ruang yang lebih menarik. 


\section{REFERENSI}

MIX MarComm. (2018). Millennials. Jakarta: Fantasious x Loveable http://ahmadbahauddin14.blogspot.com/2017/07/perilaku-dalam-arsitektur-proses-dan.html. diakses pada tanggal 20 Januari 2019.

https://www.climatelinks.org/sites/default/files/asset/document/2017_USAID_GHG\%20Emissi ons\%20Factsheet_Indonesia.pdf. diakses pada tanggal 15 Juli 2019.

www.eartheasy.com. diakses pada tanggal 20 Januari 2019.

https://en.wikipedia.org/wiki/Carbon_footprint. diakses pada tanggal 15 Juli 2019.

https://www.food.detik.com/info-kuliner/d-3389405/ini-peran-generasi-millennial-dalammembentuk-tren-makanan-2017. diakses pada tanggal 20 Januari 2019

https://www.insideindonesia.org/the-other-millennials. diakses pada tanggal 20 Januari 2019. https://www.linkedin.com/pulse/millennials-changing-architecture-from-inside-out-part-deandewhirst. diakses pada tanggal 20 Januari 2019.

https://news.mongabay.com/2009/09/indonesia-emissions-to-rise-50-by-2030-3rd-largestghg-emitter/. diakses pada tanggal 15 Juli 2019.

https://www.repository.usu.ac.id/bitstream/handle/123456789/50169/Chapter\%20II.pd;jsessi onid=5B4FA61E35B964B187E27150E76EBED3? sequence=4. diakses pada tanggal 20 Januari 2019.

http://rilis.id/10-tren-perilaku-generasi-millennials.html. diakses pada tanggal 20 Januari 2019.

https://timeforchange.org/what-is-a-carbon-footprint-definition. diakses pada tanggal $15 \mathrm{Juli}$ 2019.

https://www.womantalk.com/food/articles/7-tren-kuliner-yang-akan-populer-di-tahun-2019ygJ7B. diakses pada tanggal 20 Januari 2019.

https://www.wri.org/our-work/project/forests-and-landscapes-indonesia/climate-changeindonesia. diakses pada tanggal 15 Juli 2019.

https://www.zaenabnuraini.com. diakses pada tanggal 20 Januari 2019. 